\title{
Modelling and assessing the impact of illegal water abstractions by upstream farmers on reservoir performance
}

\author{
Nura Jafar Shanono*1, $2 \mathbb{C}$, John Ndiritu 1 \\ ${ }^{1}$ University of the Witwatersrand, Faculty of Engineering, Civil and Environmental Engineering, Johannesburg, South Africa \\ ${ }^{2}$ Bayero University Kano, Faculty of Engineering, Agricultural and Environmental Engineering, Kano, Nigeria
}

\author{
Keywords \\ Farmers \\ Illegal water abstraction \\ Reservoir performance \\ Reservoir upstream
}

\begin{abstract}
This study proposes a reservoir yield analysis that incorporates the realities of upstream illegal human activities relating to water abstraction. The study assesses the impact of such unlawful human activities on reservoir storage and yields quantitatively. A reservoir operation water balance model was simulated and coupled with upstream irrigation users' propensity to unauthorized water abstraction and set to co-evolve for the entire simulation period. The model was developed using four-state drivers (hydrological state, users' compliance, management competence and reservoir performance). The impact of human behaviour (users' and management) was assessed using 9 plausible human behaviour scenarios. The model was applied to a system of 5 reservoirs using the 90-year historical hydrologic dataset. The trajectories of the storage, yield-demand and storage-yield ratios were analyzed under different human behaviour scenarios. Both storage and yield were found to substantially decrease as users' compliance and management competence deteriorated for the same reservoir hydrological state. Depending on the scenario, the annual yield (\%) was observed to reduce from 100 to 80 or 50 or even 30 of the annual demand due to changing behaviour. Also, most of the years in which the yield differs significantly from one scenario to the other are years with shallow storage due to drought. A yield difference of about $23 \%$ was recorded between the scenarios without and with the highest unauthorized abstractions. The study, therefore, revealed how human behaviour can significantly affect reservoir storage and yield performances. This highlighted the need to be incorporating the impact of unlawful human activities into yield analysis models to quantitatively assess the impact of human behaviour on reservoir performance.
\end{abstract}

\section{INTRODUCTION}

Reservoir storage (Dam) is traditionally considered to be affected by climatic erraticism such as drought (low runoff) and evaporation losses only. These are what have been incorporated in the reservoir analysis to determine system yield capability under climatic uncertainties. However, the impact of human activities that can affect yield, though significant, are typically not explicitly incorporated into reservoir yield analysis. For example, the practice of water abstraction at reservoir upstream has been reportedly linked to the low storage and poor yield performance (van Oel et al., 2008; Shanono, 2019). Van Oel et al. (2008), revealed a water-scarcity probability of $10 \%$ as a result of reservoir upstream water abstraction. In a water-stressed country like South Africa, a water loss of even $1 \%$ should not be ignored as stressed by Bhagwan et al. (2014). Therefore, this paper reported the developed reservoir yield analysis model that can evaluate yield due to not only the estimated streamflow data as typically assumed in the yield analysis but the actual flows into the reservoirs. Thus, a socio-hydrological model for quantifying water users' propensity to compliant or unlawful behaviour relating to water use was developed and reported herein. The aim was to account for the water abstractions along the waterways at the reservoir upstream. The vital part

\footnotetext{
* Corresponding Author

*(njshanono.age@buk.edu.ng) ORCID ID 0000-0002-1731-145X (john.ndiritu@wits.ac.za) ORCID ID 0000-0001-9092-3172
}

Cite this article
Shanono, N.J., \& Ndiritu, J. (2021). Modelling and assessing the impact of illegal water abstractions by upstream farmers on reservoir performance. Turkish Journal of Geosciences 2(2), 47-54. 
of this study is, therefore, not just the abstraction, but the ethical questions surrounding the abstraction (lawful or unlawful).

Since lawful water use is usually incorporated in yield analysis (Joshi and Gupta, 2009), this modelling framework captures the causes of the water users' propensity to abstract water illegally. This is a novel approach to yield analysis that incorporated the ethics of water use and management as stressed by Groenfeldt (2013). Such an attempt to incorporate the impact of unlawful water use in the reservoir yield analysis is regarded as a real analysis that considerably minimises unnecessary needless assumptions (Ndiritu, 2005; Shanono et al., 2019). Besides, the outcomes can add value to the reservoir operational decision-making.

The study perceived to incorporate the impact of human behaviour on yield using plausible human behaviour scenarios that assimilated the tendencies for society's norms and values to change. According to Walker et al. (2001), plausible future scenarios that incorporate societal responses dynamically led to robust policies. These scenarios should incorporate the realities of the causes and effects of societal norms and values (behaviour) (Rittel and Webber, 1973; Groenfeldt, 2010). Moreover, it was suggested that reservoir planning and operational decisions should consider the uncertainties of changing water users behaviour (Muller, 2017). Thus, it is crucial to develop a yield analysis model that incorporates the co-evolutionary dynamics between users' behaviour and reservoir operation using the concept of socio-hydrology (Sivapalan et al., 2012). Socio-hydrology is an interdisciplinary area of studying human-water interactions (Montanari, et al., 2013), and recently attracted much attention (Di Baldassarre et al., 2013a, b, 2017; Viglione et al., 2014; Elshafei et al., 2014; Liu et al., 2015). However, studies relating reservoir operation to human behaviour are limited in the sociohydrological literature. Also, reservoir operation is an essential aspect of South Africa's water management and the impact of unlawful water abstraction cases are significant. Thus, a sociohydrological model that simulates and couple's reservoir operation and human behaviour using plausible scenarios to assess the impact of users' behaviour on reservoir yield could inform operational decisions. The study was therefore inspired by the need to quantitatively incorporate the impact of illegal water use into reservoir analysis thereby assessing their impact on yield. Such a novel approach to yield analysis is in line with the quest of changing water governance towards the inclusion of the reality of human behavioural impact (Montanari et al., 2013; Muller, 2017). The modelling framework in this study was built such that the level of human behaviour will vary dynamically with the reservoir hydrological state (Shanono, 2020, 2021), thereby estimating the amount of water that could be abstracted illegally at a different level of human behaviour scenarios.
The perceived factors to affect users' risk perception (RP) and water utilization pattern are reservoir hydro-climatic conditions (hydrological state). The model was thus developed using the concept of a stimuli-response system to predict water users' propensity to unlawful water use (users compliance) as explained in the theory of resilience (Forbes et al., 2013). Water managers' expertise and system facilities (management competence) are also conceived to affect the overall system yield (reservoir performance). The model quantitatively and stochastically relates these four-state drivers: i) hydrological state to users' compliance; ii) users' compliance to reservoir performance; iii) reservoir performance to management competence; and iv) management competence to reservoir hydrologic state as shown in Figure 1. This paper does not cover the detailed description and mathematical quantification of the model. It only briefly covers the conceptual basis with which the model was assembled (section 2), model application (section 3), results (section 4) and conclusions (section 5).

\section{MODEL DEVELOPMENT}

As state earlier, the reservoir operation-human behaviour socio-hydrological model was developed using four-state drivers using a stimuli-response model (black-box). The four building blocks of the coupled socio-hydrological model are briefly described below.

The first model's building block is the hydrological state (HS) which is made up of variables that can affect the storage state of the reservoir (streamflows, rainfall and evaporation). A decrease in reservoir HS is expected to generate concern and increase water users' level of risk perception (RP). According to Kinzig et al. (2013), RP can interrupt and change society's established norms and values (behaviour). Studies revealed RP due to drought increase the rate at which farmers abstract water (Elshafei et al., 2014; Firoz et al., 2017). An increase in RP can therefore drive users to disobey the water allocation rules by abstracting water without authorization. Thus, reservoir HS can affect users' propensity to lawful or unlawful activities. The causal relationships of the state drivers of the coupled model are as presented in Shanono (2021). The study therefore conceived annual relative change of rainfall $\mathrm{P}$, temperature $\mathrm{T}$, and storage $\mathrm{S}$ to serve as a surrogate to reservoir HS. Whenever reservoir HS decreases, the users' level of RP will increase and the higher the propensity to illegal water abstraction. The relative annual change in reservoir HS for a long period was computed as the difference between the mean annual value and the annual value and normalized through dividing by the mean annual value of rainfall and temperature. For the storage, the annual value is the storage state at annual decision time (April), and the mean was replaced with a given storage-state-threshold value above which no restrictions are imposed. Also, the 
negative sign was, however, assigned to temperature since an increase in temperature is not favourable to the reservoir HS. Also, these 3 variables can have a varied impact, and weights $w_{P}, w_{T}$ and $w_{S}$ are introduced to enable this variability to be effected as shown below. The modelling also further conceived and proposed two situational factors each for users and management which can affect users' level of RP (users' compliance and management competence).

$H S_{t}=f\left([\Delta P] \cdot w_{P}+[\Delta S] \cdot w_{S}-[\Delta T] \cdot w_{T}\right)$

The users' compliance (UC) factor is the $2^{\text {nd }}$ building block of the model and was introduced to represent the level of users' willingness and propensity to compliance. Willingness to comply depends on the individual's motives (self-interest or fairness), shaped by some inherent factors (Tenbrunsel and Smith-Crowe, 2008). These factors include trust, knowledge, culture, religion, social well-being and other values that shape individuals moral thinking (Treviño et al., 2006). Studies revealed a positive relationship between society's well-being and ethical practices as in accepting resource sharing policies (Tiliouine et al., 2006). More concern is expected in a less prosperous society due to a perceived threat to their quality of life, and the higher the tendency to illegal activities. The UC was also modelled to change with time in a random fashion due to the erratic nature of human behavior.

The management competence (MC) factor is the $3^{\text {rd }}$ building block of the model and comprised many other factors that affect water managers' performance. It represents the reservoir system's infrastructural development and water managers' expertise, monitoring and law enforcement unit for tackling unlawful activities. This factor aims to represent the water users' perceptions of the level of water allocation effectiveness and water managers' (Url-1). This factor can thus be affected by employees' job satisfaction. When users perceived that the water managers and supply facilities are good enough, the level of RP will reduce. Measurable parameters related to water allocation efficiency can be used as surrogates for this factor. In this study, MC was incorporated into the model dynamically and modelled using the probability density function (PDF). The moment of the distribution was varied to obtain different levels of MC. The annual users' RP was expressed as the function of reservoir HS, users' compliance (UC) and management competence (MC) as shown below. At the beginning of every water year, when RP $\leq 0$; the users' propensity to compliance increases. However, if RP > 0; propensity to compliance decreases.

$R P_{t}=f(H S, U C, M C)$

The modelling conceived how users' RP can change users' behavioural intention (BI). The BI is the individual's perceived likelihood to engage in a particular manner (Ajzen, 1991). A study revealed RP affect individuals' BI thereby eroding compliance behaviour (Gonzalez and Sawicka, 2003). The users' RP-BI was modelled as a stimuli-response system using the logistic (sigmoidal) regression function. Logistic functions are non-linear classification algorithms commonly used to classify and discriminate between two or more probable events (Komarek and Moore, 2005). The BI is therefore referred to as the probability estimate for predicting whether an action will occur. The users' RP function is the input to the logistic function, and hence users' $\mathrm{BI}$ is a function of RP using the logistic function as shown below.

Users $^{\prime} B I_{t}=f\left(\right.$ Users $\left.^{\prime} R P\right)$

The users' BI could lead to unlawful actions, and this depends on two possibilities. Firstly, the range on which the BI fall $(0 \leq B I \leq 1)$. If $B I \geq 0.5$, unlawful action may not occur, while if $B I<0.5$, unlawful action may likely occur. The users' BI is thus a threshold and binary classifier that creates a decision boundary at 0.5 such that lawful and unlawful activities are a set of 0 and 1 respectively. The second possibility for unlawful water use to occur depends on the random factor as it is not certain when the action will occur, and was used as a surrogate to the users' compliance $(0 \leq U C \leq 1.0)$. This was reflected using probability distribution and the moment of the distribution was varied to obtain different levels of users' willingness to act ethically. Hence, the occurrence or non-occurrence of illegal water use depending on the users' level of compliance (UC). The UC was also used to change the time step of the model from yearly to monthly. For a year $(i)$ in which the $B I_{i}$ predicted unlawful water use could occur, then the random variable (UC) was used to randomly specify the month $(j)$ within that year when the unlawful water use occur. Since it is unrealistic to assume that the unlawful abstraction occurs every month as summarized below.

If $\left\{\begin{array}{l}B I_{i} \geq 0.5 ; \\ B I_{i}<0.5\left\{\begin{array}{rr}\text { If } U C_{i, j}>2 * B I_{i} ; & \text { Unlawful water abstraction not occur } \\ \text { If } U C_{i, j}<2 * B I_{i} ; & \text { Unlawful water abstraction occur }\end{array}\right.\end{array}\right.$

The users' BI was modelled to determine the possibilities for illegal water use to occur. However, a variable behavioural effect (BE) was introduced to quantify the impact of these actions when they occur (proportion of water abstracted illegally). Also, the users' BE being perceived to vary with the users' RP, availability of the water at users' disposal and time, thus the response model was used to model users' response (BE) to RP and water availability. Response models are used to predict the desired behaviour to act in a specific manner. The widely used response models in ecology are the functional response models, usually used to study predator-prey interplay and are generally classified into Holling's types I, II, and III (Holling, 1959). These models are used to model the intake rate of a predator as a 
function of the food density (prey), the rate of the prey-predator encounter and the time is taken before processing the food (Aljetlawi et al., 2004). The RP-BE response was therefore related to when a hungry predator is looking for food. Hence, the magnitude of users' BE due to unlawful water use was related to the level of users' RP, availability of water at users' disposal and time to use the illegally abstracted water. But, the time was simply considered as deterministic due to simulation time steps. The Hollings type II functional response model was found to be suitable to model BE as a function of $\mathrm{RP}$, water availability and simulation time interval as shown below.

Users $^{\prime} B E_{t}=f(R P$, Water Availability, Time Interval $)$

The modelling also created a link for assessing the impact of users' BE on reservoir performance by coupling users' BE with the reservoir mass balance variables. This aims to account for the unlawful water use along the streamflows and other waterways. Such a paradigm of yield analysis that accounts for the impact of human behaviour is expected to help minimize unnecessary assumptions in yield analysis. Reservoir storage determines the amount of water to be released, and releases are determined to satisfy demands. In reservoir operation, either the system is capable of satisfying the demand or can only satisfy a portion of the demand. In the latter case, restriction measures are normally implemented, and the extent of these restrictions depend on the storage state, operating rules and the set supply reliabilities. Depending on the level of reservoir hydrological state, users' compliance and management competence, the delivered supply $\left(R_{d}\right)$ may be equal to or less than the allocated supply $\left(R_{a}\right)$. When users' compliant was high and effective management, it is expected that the delivered supply will equal the allocated supply and streamflows into the reservoirs $\left(Q_{d}\right)$ will be as expected $\left(Q_{e}\right)$ without upstream illegal abstraction. Conversely, when the users' tendency to unlawful activities is high and ineffective management, the delivered supply can be less than the allocated supply and streamflows can also reduce due to unlawful abstraction along supply waterways and reservoir upstream respectively. The delivered supply and streamflows to the reservoir are respectively as expressed below.

$R_{d}= \begin{cases}R_{a} & ; \text { If unlawful abstractions are negligible }\end{cases}$ $R_{d}=\left\{\begin{array}{cc}R_{a} & ; \text { If unlawf } \\ (1-B E) R_{a} ; \text { If unlawful abstractions are significant }\end{array}\right.$

$Q_{d}= \begin{cases}Q_{e} & \text {; If unlawful abstractions are negligible } \\ (1-B E) Q_{e} & \text { iff unlawful abstractions are significant }\end{cases}$

Management competence (MC) in rectifying users' BE was modelled and incorporated into the model to serve as feedback (intervention measures). Whenever reservoir performance deteriorates due to $\mathrm{BE}$, the management usually responds using intervention measures. In the field of human resource management, the normal distribution has been found to fit management performance data accurately (Sarkar et al., 2011). Depending on the employees' work engagement, the normal distribution can skew to right or left indicating ineffective or effective MC. The MC was thus modelled using probability density function (PDF), and the moment of this distribution was varied to obtain different levels of MC. Let MC and 1-MC be interpreted as the probabilities that the system is protected from, and vulnerable to the users' BE. For simplicity, a linear relationship was used to relate how MC suppresses the negative effect of $\mathrm{BE}$ on reservoir performance. The $\mathrm{BE}\left(0 \leq B E_{t} \leq B E_{\max }\right)$ for a given level of $\mathrm{MC}$ at a particular time $(0 \leq$ $M C_{t}<1$ ) are linearly related as the product of the $\mathrm{BE}$ and the probability that the system is vulnerable to the BE $(1-M C)$ as shown below.

Actual Users' $B E_{t}=f([B E] *[1-M C])$

\section{SIMULATION OF RESERVOIR OPERATION COUPLED WITH USER BEHAVIOURAL EFFECT (BE)}

The reservoir operation-human behaviour model was simulated and applied to a hypothetical but realistic system of 5 reservoirs (Olifants River Reservoir System) using a 90-year historical monthly hydrological dataset. The hydrological aspect is thus real while the social aspect (users' tendency to illegally use water) was hypothetically incorporated using scenarios. The mass balance as affected by users' BE at reservoir upstream is described in equation. 1 . Also, the total allocated and delivered supplies are as expressed in equations. 2 and 3 respectively.

$S_{t+1}=\sum_{k=1}^{N} S_{t, k}+\left(1-B E_{t, k}\right) Q_{t, k}-R_{t, k}-N E_{t, k}-S P_{t, k}$

$R_{a}=\sum_{t=1}^{T} \sum_{k=1}^{N} R_{t, k}$

$R_{d}=\sum_{t=1}^{T} \sum_{k=1}^{N}\left(1-B E_{t, k}\right) R_{t, k}$

Where: $S_{t+1}$, $=$ total system storage, $S_{t, k}=$ initial storage of reservoir $k$; $Q_{t, k}=$ inflow to reservoir $k$; $R_{t, k}=$ allocated supply from reservoir $k \cdot B E_{t, k}=$ users' behavioural effect at reservoir $k . N E_{t, k}$ and $S P_{t, k}=$ net evaporation losses and spills out of reservoir $k ; R_{a}$ and $R_{d}=$ total allocated and delivered supplies. $\mathrm{t}=$ monthly.

Reservoir yield (Y) performance is the $4^{\text {th }}$ building block of the model which is the ratio of the total delivered supplies to the total streamflows into the system for the entire simulation period under various levels of human behaviour scenarios. This aims to identify the extent to which the system is affected for a long period of time due to co-evolving dynamics between unlawful water abstraction and system performance as expressed in equation. 4 . 
$Y=\frac{\sum_{i=1}^{T} \sum_{j=1}^{12} \sum_{k=1}^{N} R d_{i, j, k}}{T R}$

Where: $Y=$ yield, $R d_{i, j, k}=$ delivered supply in month $j$ of year $i$ for reservoir $k . N$ and $T=$ number of reservoirs in the system and number of years of simulation. $T R=$ total runoff for the entire simulation period.

The human behaviour scenarios were formulated to enable assessment of the impacts of changing users' compliance (UC), management competence (MC) and hydrological state (HS) on reservoir yield. Nine scenarios are created from different combinations of 3 categories of UC and MC as shown in Table 1. Also, a 90-year historical monthly hydrological dataset was used to reflect the natural variability of HS. The system was also simulated without incorporating the human behaviour scenario as typically assume in yield analysis and used as a reference to the other scenarios.

Table1. Summary of the human behaviour scenarios

\begin{tabular}{|c|c|c|c|c|c|c|}
\hline \multirow{2}{*}{ SC } & \multicolumn{3}{|c|}{3 Levels of Scenario Building-Blocks } & \multicolumn{3}{|c|}{ Range of values } \\
\hline & HS & UC & MC & HS & UC & $\mathrm{MC}$ \\
\hline 1 & \multirow{3}{*}{$\begin{array}{l}\text { Favourable } \\
\text { Moderately favourable } \\
\text { Unfavourable }\end{array}$} & Lawful & Effective & \multirow{3}{*}{ NV } & $0.7<\mathrm{UC} \leq 1.0$ & $0.7<\mathrm{MC} \leq 1.0$ \\
\hline 2 & & Moderately lawful & Effective & & $0.5 \leq \mathrm{UC} \leq 0.7$ & $0.7<\mathrm{MC} \leq 1.0$ \\
\hline 3 & & Unlawful & Effective & & $\mathrm{UC} \leq 0.5$ & $0.7<\mathrm{MC} \leq 1.0$ \\
\hline 4 & \multirow{3}{*}{$\begin{array}{l}\text { Favourable } \\
\text { Moderately favourable } \\
\text { Unfavourable }\end{array}$} & Lawful & Moderately effective & \multirow{3}{*}{ NV } & $0.7 \leq \mathrm{UC} \leq 1.0$ & $0.5 \leq \mathrm{MC} \leq 0.7$ \\
\hline 5 & & Moderately lawful & Moderately effective & & $0.5 \leq \mathrm{UC} \leq 0.7$ & $0.5 \leq \mathrm{MC} \leq 0.7$ \\
\hline 6 & & Unlawful & Moderately effective & & $\mathrm{UC} \leq 0.5$ & $0.5 \leq \mathrm{MC} \leq 0.7$ \\
\hline 7 & \multirow{3}{*}{$\begin{array}{l}\text { Favourable } \\
\text { Moderately favourable } \\
\text { Unfavourable }\end{array}$} & Lawful & Ineffective & \multirow{3}{*}{ NV } & $0.7<\mathrm{UC} \leq 1.0$ & $\mathrm{MC}<0.5$ \\
\hline 8 & & Moderately lawful & Ineffective & & $0.5 \leq \mathrm{UC} \leq 0.7$ & $\mathrm{MC}<0.5$ \\
\hline 9 & & Unlawful & Ineffective & & $\mathrm{UC}<0.5$ & $\mathrm{MC}<0.5$ \\
\hline 0 & \multicolumn{6}{|c|}{ Users' behavioural effects (BE) not incorporated } \\
\hline
\end{tabular}

HS: hydrological state UC: users' compliance MC: management competence NV: depends on natural variability of the hydrologic data SC: scenario

\section{SIMULATION RESULTS}

The result discussion was limited to 3 scenarios: scenario with no BE (nBE - scenario 0), least BE (lBE - scenario 1) and highest BE (hBE - scenario 9) as these provided the needed information on how unauthorized water abstractions at reservoir upstream impacted the reservoir performance. The $\mathrm{nBE}$ scenario result was used as a reference to the results of other scenarios with different levels of BE. The trajectories of the storage state, yield/demand ratio and storage-yield trade-off for the 90-year monthly simulated data were analysed. The aim was to dynamically assess the impact of unauthorized water abstractions on storage state and yield, thereby understanding the co-evolving dynamics between unauthorized water abstractions and reservoir performance for a long period. The analysis is presented on an annual basis since the reservoir operation socio-hydrological model incorporates hydrological variables annually. The analysis was also limited to the total storage since it was computed as the weighted linear average of all the 5 reservoirs and hence provides a real picture of the system. Besides, reservoir operating rules consider the state of the total storage before allocating water from any reservoir.

Figure 1 illustrates the trajectories of the annual storage state (\%) of the total storage at the beginning of every water year (April). Storage state at the beginning of the water year was chosen as it provides a hint on the proportion of the annual target draft to be released within that year and the amount of water loss due to illegal use can be traced at different behaviour scenarios. The total storage trajectories were found to differ due to the impact of unlawful abstraction along the streamflows for the nBE, lBE and hBE scenarios. The unlawful use effect was first shown in the $8^{\text {th }}$ year (marked A) in which the total storage state for scenarios 1 and 9 was found to be slightly lower than that of scenario 0 . There were about 12 major instances in which unlawful abstractions was found to significantly affect the total storage state (marked A to L). The impact of unlawful abstraction on the storage was found to lasts for 1 to 2 years in case $A, B, H, J, K$ and L and 3 to 5 years in case C, D, E, F, G and I. A total of 25 years were observed to be affected by unlawful water abstraction. Since the simulation is for 90-year data, the major effect of unlawful abstraction on storage can be said to occur once every 8 years $(90 / 12)$ with 1 year affected in every 4 years $(90 / 25)$.

Since the reservoir operating rule considers the state of the total storage before allocating water from any reservoir, the overall system yield can therefore be affected by the total storage state. Although, depending on the storage state of a given reservoir and its location within the system, not all the identified incidents can lead to a substantial reduction of water supplies from that reservoir. For example, incidents $\mathrm{A}, \mathrm{B}, \mathrm{C}$ and $\mathrm{J}$ in which the difference in the storage state between the nBE and hBE scenarios was not significant, this may not likely 
affect the amount of water to be allocated. However, in incident $\mathrm{D}$, the storage state for the $\mathrm{nBE}$ and $\mathrm{hBE}$ scenarios differs significantly and the annual allocation could reduce from $50 \%$ to $30 \%$ of the annual target draft. Other similar cases can be spotted at incidents $\mathrm{E}, \mathrm{F}$ and $\mathrm{G}$ in which the annual allocation could reduce from $80 \%$ to $50 \%$ or even to $30 \%$ of the annual target draft. Hence, reservoir yield can reduce whenever massive unlawful water abstraction occurs at the reservoir upstream. Most of the years in which the storage state differs due to changing human behaviour are the years with poor storage state (below 70\%). Thus, the model reveals that unlawful abstractions are likely to occur during a poor hydrological state.

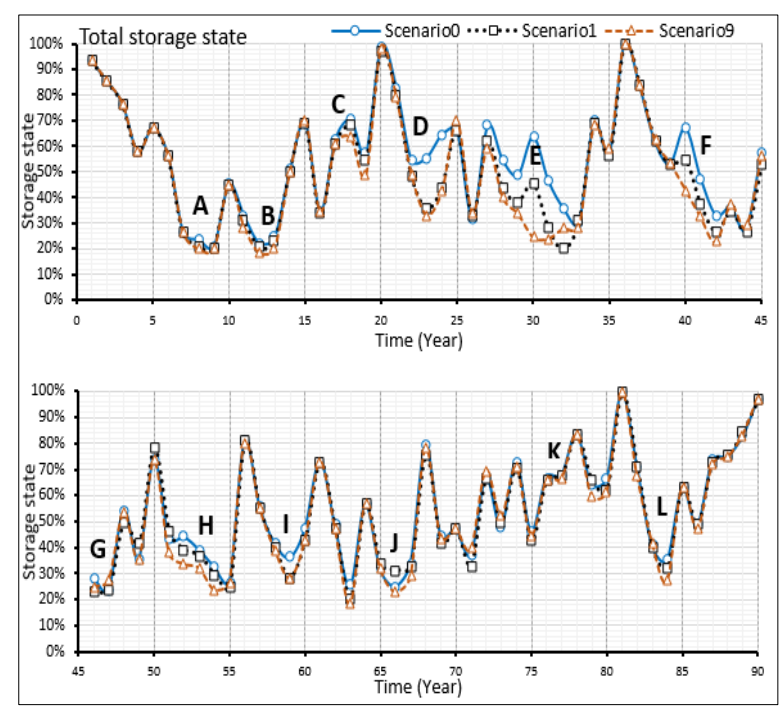

Figure 1 Annual total storage state trajectory for scenarios 0,1 and 9

Figure 2 shows the trajectories of the total storage state on decision month (April) and the percentage of the annual demand that has been delivered (yield) for scenarios 0, 1 and 9. The aim was to relate annual storage to yield at different scenarios. Most of the years in which the yield found to significantly differ from one scenario to the other are the years with poor storage (droughts), and this agrees with the observation that drought increases water consumption due to perceived risk and threat to their quality of life (Elshafei et al., 2014; Firoz et al., 2017). An excellent example is in the $30^{\text {th }}$ year marked $X$ in which about $89 \%, 67 \%$ and $37 \%$ of the total annual target draft were found to be delivered in the $\mathrm{nBE}, \mathrm{lBE}$ and hBE scenarios respectively. The result indicates that for a given year that experience massive unlawful water abstractions, water supply can drastically reduce to even less than half of the anticipated supply. Although there were very few years in which water supply reductions could occur, there are a considerable number of years in which illegal water abstraction affected the storage and yield substantially. It is therefore crucial for the management to ensure effective compliance by the users particularly in the years of the poor hydrological state.

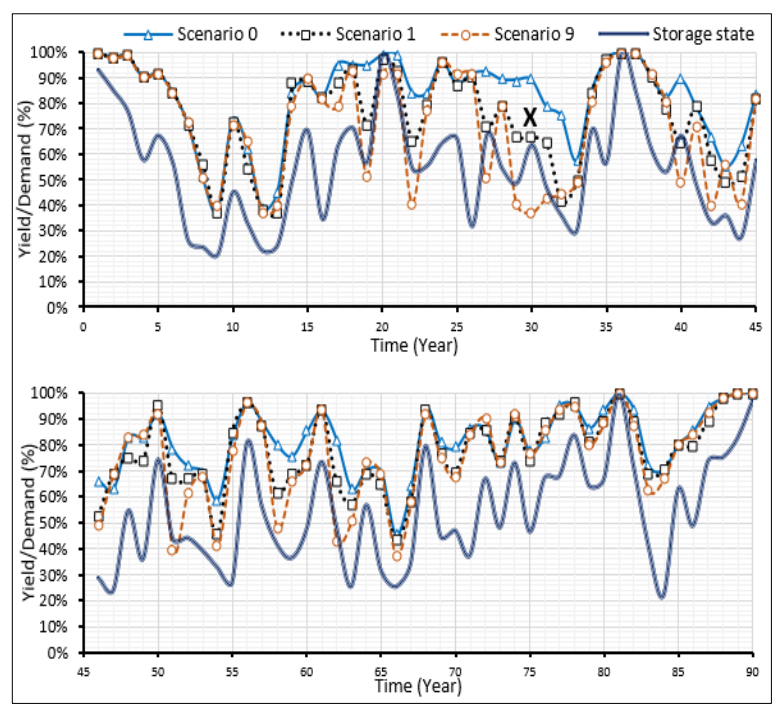

Figure 2: Yield/demand ratio and storage state trajectory for scenarios 0,1 and 9

Figure 3 shows the total storage volume and yield trajectories of the results obtained from the simulation for scenarios 0,1 and 9. The aim was to relate and assess how annual yield changes as the annual storage volume change under different human behaviour scenarios. Less water is lost through unlawful abstractions as the storage state improves as all the trend lines tend to join together as the storage volume improves.

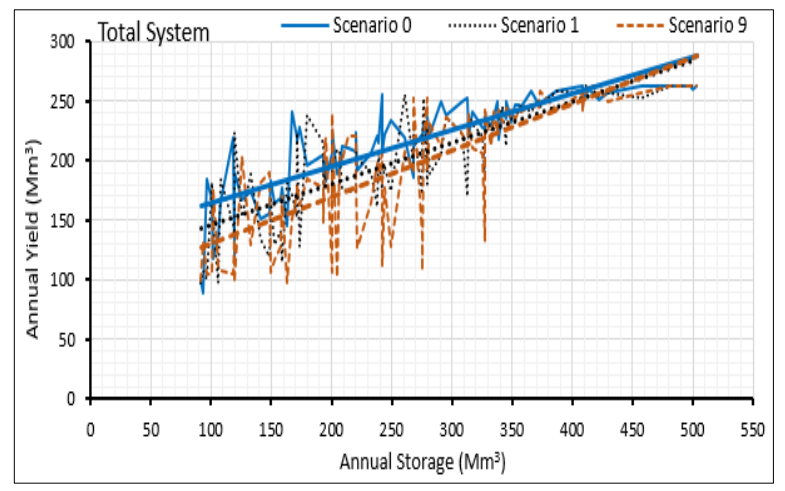

Figure 3: Storage-Yield trade-off as affected by human behaviour

For example, when the total annual storage volume was $150 \mathrm{Mm}^{3}$, the total system yield for the scenarios with no, least and highest BE (scenario 0,1 and 9) were $138 \mathrm{Mm}^{3}, 119 \mathrm{Mm}^{3}$ and $106 \mathrm{Mm}^{3}$ respectively. The calculated reduction in yield was $32 \mathrm{Mm}^{3}$ (23\%) between $\mathrm{nBE}$ and hBE scenarios. Whereas, when the total storage volume was 350 $\mathrm{Mm}^{3}$, the total system yield for all the three scenarios was nearly the same $\left(240 \mathrm{Mm}^{3}\right)$. The total system yield and the storage volume can thus be affected substantially by human behaviour through illegal water use as previously observed. 


\section{CONCLUSIONS}

The study developed a reservoir operation socio-hydrological simulation model that couples and dynamically co-evolves reservoir operation and water users' propensity to unlawful water use. The aim was to get insight into the co-evolving dynamics due to interactions between upstream unauthorized water use and reservoir performance. The trajectories of the storage were analysed at different human behaviour scenarios for 90-year simulated data. The storage was found to be decreasing as human behaviour deteriorated due to unlawful water abstractions. The study revealed that the effect of unlawful abstraction on storage occurred once every 8 years with 1 year affected every 4 years. Also, annual supplies were observed to reduce from $100 \%$ to $80 \%$ or $50 \%$ or even $30 \%$ of the annual target draft due to changing behaviour. The analysis revealed that most of the years in which the yield differs significantly from one scenario to the other are years with shallow storage (drought years). A yield difference of about $23 \%$ was recorded between the scenarios without and with the highest behavioural effects. Finally, the study demonstrated how human behaviour can significantly affect reservoir storage and yield performance. This stresses the need to be incorporating the realities of unlawful human activities relating to water abstraction into reservoir analysis to quantitatively assess the impact of human behaviour on yield.

\section{Author Contributions}

Nura Jafar Shanono: conceptualization, methodology, data generation from the model and writing. John Ndiritu: supervision, reviewing and editing.

\section{Conflicts of Interest}

The authors declare no conflict of interest.

\section{REFERENCES}

Ajzen, I. (1991). The theory of planned behaviour. Organizational Behavior and Human Decision Processes, 50(2), 179-211.

Aljetlawi, A.A., Sparrevik, E., \& Leonardsson, K. (2004). Prey-predator size-dependent functional response: derivation and rescaling to the real world. Journal of Animal Ecology, 73(3), 239-252.

Bhagwan, J., Wegelin, W., McKenzie, R., \& Wensley, A. (2014). Counting the lost drops: South Africa's study into non-revenue water. Water Practice and Technology, 9(4), 502-508.

Di Baldassarre, G., Kooy, M., Kemerink, J.S., \& Brandimarte, L. (2013a). Towards understanding the dynamic behaviour of floodplains as human-water systems. Hydrology and Earth System Sciences, 17(8), 3235-3244.

Di Baldassarre, G., Viglione, A., Carr, G., Kuil, L., \& Salinas, J.L. (2013b). Socio-hydrology: conceptualising human-flood interactions. Hydrology and Earth System Sciences, 17(8), 3295-3303.

Di Baldassarre, Giuliano, Martinez, F., Kalantari, Z., \& Viglione, A. (2017). Drought and flood in the Anthropocene: feedback mechanisms in reservoir operation. Earth System Dynamics, 8(1), 225-233.

Elshafei, Y., Sivapalan, M., Tonts, M., \& Hipsey, M.R. (2014). A prototype framework for models of socio-hydrology : identification of key feedback loops and parameterisation approach. Hydrology and Earth System Sciences, 18(6), 2141-2166.

Firoz, A.B.M., Nauditt, A., Fink, M., \& Ribbe, L. (2017). Quantifying human impacts on hydrological drought using a combined modelling approach in a tropical river basin in Central Vietnam. Hydrology and Earth System Sciences Discussion, 22(1), 547-565.

Forbes, B.C., Fresco, N., Shvidenko, A., Danell, K., \& Stuart, F. (2013). Geographic Variations in Anthropogenic Drivers that Influence the Vulnerability and of Social-Ecological Resilience Systems. AMBIO: A Journal of the Human Environment, 33(6), 377-382.

Gonzalez, J.J., \& Sawicka, A. (2003). The role of learning and risk perception in compliance. In Proceedings of the 21st International Conference of the System Dynamics Society, New York.

Groenfeldt, D. (2010). The next nexus: Environmental ethics, water management and climate change. Water Alternatives, 3(3), 575.

Groenfeldt, D. (2013). Water Ethics: A values approach to solving the water crisis (First Edit). Routledge.

Holling, C.S. (1959). The components of predation as revealed by a study of small-mammal predation of the European Pine Sawfly1. The Canadian Entomologist, 91(5), 293-320.

Joshi, G.S., \& Gupta, K. (2009). A simulation model for the operation of a multipurpose multi-reservoir system for River Narmada, India. Journal of Hydro-Environment Research, 3(2), 96-108.

Kinzig, A.P., Ehrlich, P.R., Alston, L.J., Arrow, K., Barrett, S., Buchman, T.G., ... \& Saari, D. (2013). 
Social norms and global environmental challenges: the complex interaction of behaviors, values, and policy. BioScience, 63(3), 164-175.

Komarek, P., \& Moore, A.W. (2005). Making logistic regression a core data mining tool: A practical investigation of accuracy, speed, and simplicity.In Institute, Carnegie Mellon University.

Liu, D., Tian, F., Lin, M., \& Sivapalan, M. (2015). A conceptual socio-hydrological model of the coevolution of humans and water: a case study of the Tarim River basin, western China. Hydrology and Earth System Sciences, 19(2), 1035-1054.

Montanari, A., Young, G., Savenije, H.H.G., Hughes, D., Wagener, T., Ren, L.L., ... \& Z. Balyaev, V. (2013). "Panta Rhei-Everything Flows": Change in hydrology and society-The IAHS Scientific Decade 2013-2022. Hydrological Sciences Journal, 58(6), 1256-1275.

Muller, M. (2017). Understanding the origins of Cape Town's water crisis. Civil Engineering= Siviele Ingenieurswese, 2017(5), 11-16.

Ndiritu, J.G. (2005). Maximising water supply system yield is subject to multiple reliability constraints via simulation-optimisation. Water SA, 31(4), 423-434.

Rittel, H.W.J., \& Webber, M.M. (1973). Dilemmas in a general theory of planning. Policy Sciences, 4(2), 155-169.

Sarkar, A., Mukhopadhyay, A.R., \& Ghosh, S.K. (2011). Comparison of performance appraisal score: A modified methodology. Research and Practice in Human Resource Management, 19(2), 92-100.

Shanono, N.J. (2019). Assessing the Impact of Human Behaviour on Reservoir System Performance Using Dynamic Co-evolution, A PhD Thesis Submitted to University of the Witwatersrand, Johannesburg.

Shanono, N.J. (2020). Applying the concept of sociohydrology to assess the impact of human behaviour on water management sectors: A review. Bayero J.of Eng \& Tech, 15(2), 105-116.

Shanono, N.J. (2021). Co-evolutionary dynamics of human behaviour and water resource systems performance: a socio-hydrological framework. Academia Letters.

Shanono, N.J., Nasidi, N.M., Maina, M.M., Bello, M.M., Ibrahim, A., Umar, S.I., ... \& Putra, U. (2019). Socio-hydrological study of water users' perceptions on the management of irrigation schemes at Tomas irrigation project, Kano, Nigeria. Nig J. Eng, Sci \& TECH, 5(2), 139-145.

Sivapalan, M., Savenije, H.H.G., \& Blöschl, G. (2012). Socio-hydrology: A new science of people and water. Hydrological Processes, 26(8), 12701276.

Tenbrunsel, A.E., \& Smith-Crowe, K. (2008). Ethical decision making: where we've been and where we're going. The Academy of Management Annals, 2(1), 545-607.

Tiliouine, H., Cummins, R.A., \& Davern, M. (2006). Measuring wellbeing in developing countries: The case of Algeria. Social indicators research, 75(1), 1-30.

Treviño, L.K., Weaver, G.R., \& Reynolds, S.J. (2006). Behavioural Ethics in Organizations: A Review. Journal of Management, 32(6), 951-990.

Van Oel, P.R., Krol, M.S., Hoekstra, A.Y., \& De Araújo, J.C. (2008). The impact of upstream water abstractions on reservoir yield: The case of the Orós Reservoir in Brazil. Hydrological Sciences Journal, 53(4), 857-867.

Viglione, A., Di, G., Brandimarte, L., Kuil, L., Carr, G., Luis, J., Scolobig, A., \& Blöschl, G. (2014). Insights from socio-hydrology modelling on dealing with flood risk-roles of collective memory, risktaking attitude and trust. Journal of Hydrology, 518, 71-82.

Walker, W.E., Rahman, S.A., \& Cave, J. (2001). Adaptive policies, policy analysis, and policymaking. European Journal of Operational Research, 128(2), 282-289.

Url-1:

http://www.dwa.gov.za/Masibambane/docum ents/structures/wsslg/may10/WSLG TT Report Version 01.pdf (last accessed 27 June 2021) 